\title{
然
}

Ramón Casilda Béjar*

\section{LA ACTIVACIÓN DEL TEJIDO EMPRESARIAL ESPAÑOL DESDE EL PACTO VERDE DE LA UNIÓN EUROPEA}

La pandemia de la COVID-19 ha generado una crisis sin precedentes que afecta especialmente a la economía y a las empresas españolas. Las características del tejido empresarial español, con un fuerte predominio de microempresas y pymes, de productividad reducida y especializada en algunos de los sectores más afectados por la crisis, aconsejan su reestructuración y reactivación. La reestructuración del tejido productivo, que requiere un amplio consenso y colaboración a largo plazo, debe alinearse con el Pacto Verde Europeo y la digitalización como pilares básicos del crecimiento económico. Propongo la creación del «Instituto Verde y Digital de la Pequeña y Mediana Empresa».

Palabras clave: productividad, especialización, pymes, I+D, Mittelstand, COVID-19. Clasificación JEL: J24, O32, 047.

\section{Identificación del tema}

Aún se sentía el legado del prolongado periodo recesivo de la «crisis» de las subprime o hipotecas basura que comenzó en Estados Unidos, en agosto de 2007, y que ocasionó descensos desconocidos del producto interior bruto (PIB) y una recesión de la economía mundial como no se había conocido desde la década de 1930 con la Gran Depresión.

Ahora, en 2020, una inesperada «crisis» impacta y sacude con mucha mayor intensidad y virulencia la economía española y mundial. Esta vez, por la llegada súbita de un cisne

*Profesor del Instituto Universitario de Investigación en Estudios Latinoamericanos de la Universidad de Alcalá. Profesor del Instituto de Estudios Bursátiles. Consultor Estratégico Iberoamericano.

Versión de junio de 2020.

DOI: https:/doi.org/10.32796/bice.2021.3131.7146 amarillo desde la ciudad de Wuhan (China), que está demostrando las gravísimas consecuencias económicas, empresariales, laborales, sociales y humanitarias que conlleva la economía de la salud'.

Nos enfrentamos, pues, a una crisis sin precedentes, la pandemia del coronavirus o la COVID-19², que perturba con intensidad el orden económico de nuestro país a una velocidad y escala desconocida desde la Guerra $\triangleright$

\footnotetext{
Para más detalle sobre economía y COVID-19, véase https://www. eleconomista.es/autor/Ramon-Casilda-Bejarhttps://blogs.elconfidencial. com/economia/tribuna/2020-04-09/sobrepasamiento-fondo-compensacioneuropeo-covid19_2540963

2 La aparición de la COVID-19 ha puesto en evidencia que cuando destruimos la biodiversidad, destruimos el sistema que sustenta la vida humana. A nivel mundial, mil millones de personas son contagiadas cada año y millones de ellas mueren debido a las enfermedades causadas por los coronavirus; y alrededor de un $75 \%$ de todas las enfermedades infecciosas emergentes en humanos son zoonóticas, lo que significa que se transmiten de animales a personas. La naturaleza nos está enviando un mensaje.
} 
Civil. Incorporando una complejidad tan enorme, que la gran cantidad de hechos, más allá de los estrictamente económicos, nos hacen ver que estamos ante una situación económica «única».

Así lo constata el Fondo Monetario Internacional (FMI), que, en la actualización de su informe «Perspectivas de la economía mundial» (WEO, octubre de 2020), esta se contraerá un $4,4 \%$ en 2020 . Lo que supone una ligera mejora con respecto a la última perspectiva de junio de 2020, y en parte se debe a la rápida reapertura de China y los estímulos en los países ricos a raíz de la pandemia del coronavirus. A pesar de esta leve mejora, el FMl advierte que la recuperación económica «probablemente será larga, desigual e incierta».

España sufrirá el mayor retroceso de las economías avanzadas, ya que su PIB caerá un $12,8 \%$. Sin embargo, los pronósticos para 2021 son más optimistas, ya que se espera que crezca un 7,2\%. En 2020, en las otras llamadas «economías avanzadas», como Estados Unidos (-4,3\%), Alemania $(-6,0)$, Japón $(-5,3)$ o Reino Unido $(-9,8 \%)$, la caída del PIB será menor. China, en cambio, evitará la recesión, con un aumento del PIB real del 1,9\%. Las dos principales economías latinoamericanas, Brasil y México, registrarán una contracción del $5,8 \%$ y del $9 \%$, respectivamente. En 2021 se prevé que las economías de ambos países experimenten una recuperación: México, un 3,5\%; y Brasil, un 2,8\%.

De manera que, en concordancia con el comportamiento de la economía, la destrucción de empresas también es bastante mayor que en otros países de nuestro entorno, lo que indica la existencia de unas condiciones particulares que limitan la fortaleza y la capacidad de resistencia del tejido empresarial español. Situación que ahonda en la apremiante necesidad de transformación estructural de la economía española.

Para que dicha transformación estructural de la economía española sea efectiva deben introducirse cambios relevantes en la estructura productiva. Estos cambios alteran por completo el crecimiento económico, queremos decir, tanto en el sector privado como en el público. En el primero, con mayor intensidad, puesto que es el que más contribuye al aumento de la renta per cápita.

Queda claro, pues, que, ante la inmensa y veloz caída del tejido empresarial, y, en consecuencia, la destrucción masiva de puestos de trabajo, resulta esencial evitar el colapso productivo y económico. Por tanto, junto con los necesarios como indispensables apoyos e incentivos públicos, las empresas son la clave para detener el deterioro acelerado de la economía española y frenar el desempleo y la pérdida de rentas que rebajan la capacidad de consumo.

Abro nota. La teoría del consumo, introducida por John M. Keynes en 1936, nos indica que la renta disponible corriente (es decir, la que se obtiene anualmente después de descontar los impuestos) es el factor más importante para determinar el consumo. El propio Keynes estableció una «ley psicológica», donde las personas vinculan estrechamente su gasto a su renta. Si deseamos que la locomotora de la economía comience a funcionar, hay que proteger las rentas de las familias, pero para ello tenemos que ayudar a empresas y empresarios, porque eso es lo que nos dará crecimiento del empleo y estimulará el consumo, y, por tanto, nos ayudará a superar esta crisis. Cierro la nota.

En esta situación, las empresas son la clave: grandes, medianas y pequeñas. Todas dependen -aunque las más grandes disponen de $\triangleright$ 
mayores medios - de la capacidad para dotarse de los recursos que les permitan aumentar sus ventajas competitivas basadas en la productividad, la calidad y la innovación.

Pero debemos tener en cuenta que el tejido empresarial español cuenta mayoritariamente con unidades de menor tamaño, como son las micro, pequeñas y medianas empresas, cuya consolidación y crecimiento representan una debilidad que no es nada fácil de superar.

Entre los factores que las investigaciones identifican como claves para conseguirlo destacan: capital, productividad, tecnología e innovación. Además, el grado de internacionalización representa una condición fundamental para poder competir y sobrevivir en un mundo globalizado.

Otro factor esencial es que carecen de una financiación adecuada según las necesidades de cada empresa y de cada sector. De hecho, en el origen de las dificultades que sufrió el tejido empresarial español durante la Gran Recesión estuvo la restricción del crédito. Las empresas españolas destacan por la acusada dependencia del crédito bancario y más aún, en el caso de las pequeñas y medianas, que lo sufren con más intensidad ante la crisis tan impactante en términos económicos y financieros de la COVID-19.

En este caso, el Instituto de Crédito Oficial (ICO) ha desarrollado una intensa labor para la puesta en marcha y gestión de la línea de avales aprobada por el Gobierno, en marzo de 2020 (RDL 8/2020), para facilitar el acceso a la liquidez de autónomos y empresas de todos los tamaños y sectores afectados para hacer frente al impacto económico y social de la COVID-19. Ha sido un caso de éxito de colaboración público-privada y corresponsabilidad entre Administración, entidades financieras, empresas y autónomos, que ha permitido inyectar financiación al tejido productivo.
De acuerdo con los datos disponibles hasta el 30 de noviembre de 2020, las entidades financieras han registrado ante el Instituto de Crédito Oficial un total de 909.627 operaciones de financiación, por un importe avalado de 77.613 millones de euros, que han permitido la concesión de 84.327 millones de euros de financiación a autónomos y empresas. El $98 \%$ de las operaciones (892.358) son solicitudes para financiación de autónomos y pymes por un importe total avalado de 61.991 millones de euros, que han permitido canalizar $77.558 \mathrm{mi}-$ llones de euros de financiación. Asimismo, se han avalado 17.269 operaciones de grandes empresas, por importe de 22.336 millones de euros, que les han permitido obtener financiación por 33.413 millones de euros.

Una nueva línea de avales fue aprobada por el Gobierno en julio de 2020 (RDL 25/2020), gestionada igualmente por el ICO, dotada con 40.000 millones de euros, que complementa al programa anterior. La novedad es que está destinada principalmente a impulsar la recuperación y robustecer la competitividad internacional de las empresas, cubriendo necesidades de gastos corrientes y de capital y promoviendo nuevas inversiones tanto para adaptar, ampliar o renovar sus capacidades productivas, como para reiniciar su actividad empresarial.

De todas maneras, la realidad demuestra que aunque estas ayudas han resultado importantes para frenar la caída de empresas de todos los niveles, mayoritariamente de pymes, las diferentes estadísticas oficiales, así como las de organizaciones empresariales, demuestran que la destrucción de pymes resulta bastante superior a la que se produce en países de nuestro entorno de la Unión Europea.

Así que podemos preguntarnos: ¿por qué en otros países de la Unión Europea las pymes muestran mejores resultados que en $\triangleright$ 
España? Es el caso de las Mittelstand, las pymes alemanas. Las Mittelstand son empresas de carácter familiar, cuentan con una buena financiación y están enfocadas a la innovación y la internacionalización. El ejemplo más próximo de su fortaleza lo encontramos en la anterior crisis, cuando demostraron no solo ser capaces de resistir la Gran Recesión, sino que lograron salir más robustecidas y competitivas.

\section{Estructura y características del tejido empresarial español}

A partir de los años cincuenta del siglo xx, el poder económico ha sido controlado y ejercido por Estados Unidos, Japón y algunos países europeos, como Alemania, Gran Bretaña o Francia. Pero Estados Unidos resultó ser el gran triunfador y se afianzó como «líder y primera potencia mundial», hasta que desde los primeros años del nuevo siglo xxı comenzaron a posicionarse con fuerza nuevos actores, siendo el caso más destacado el de China.

En este contexto, las grandes empresas españolas se internacionalizaron y se hicieron globales, en algunos casos como líderes mundiales o regionales, como en América Latina. Por su parte, las pequeñas y medianas empresas, aunque no siguieron en igual medida esta trayectoria, sin embargo, también se han internacionalizado, aunque con distinta intensidad, y sobre todo las medianas.

De cómo se estructura el tejido empresarial español tenemos que tener muy en cuenta que España es un país donde sobresale el sector servicios. Según la Contabilidad Nacional Trimestral del Instituto Nacional de Estadística (INE), su peso en el PIB (excluyendo impuestos menos subvenciones sobre los productos) supuso el $74,31 \%$ en el tercer trimestre de
2020 y 14.508 .800 empleos, según la Encuesta de Población Activa (EPA) ${ }^{3}$. La industria tiene el $14,0 \%{ }^{4}$ (2.687.700 empleos), la construcción, el 6,5\% (1.249.300 empleos) ${ }^{5}$ y la agricultura, el 3,8\% (731.100 empleos). Por subsectores más específicos, entre el comercio y la hostelería aglutinan el $23,3 \%$ del total de ocupados.

Para la economía de cualquier país, el tejido empresarial es lo más importante, quizás lo más importante. Y las iniciativas de las políticas y los agentes económicos (básicamente privados) son los que le otorgan la capacidad productiva y competitiva, adaptándose a los cambios en la demanda y tratando de ser competitivos a lo largo del tiempo (Sequeiros, 2019) ${ }^{6}$.

Participamos de la idea de que el tejido empresarial español debe modificar su sistema productivo. Para lograrlo, se impone que priorice la caja negra de la «productividad». Esto requiere de mayor inversión en investigación y desarrollo $(I+D)^{7}$, íntimamente relacionada con la disponibilidad del conocimiento necesario para generarlo.

Hay que tener en cuenta que las empresas que más crecen son aquellas que realizan un esfuerzo considerable en la investigación y desarrollo de nuevos productos o en mejoras de calidad de los ya existentes. La aplicación de más y mejores recursos a las actividades de I+D permite aumentar la tasa a la que tiene lugar el $\triangleright$

\footnotetext{
3 Porcentualmente, los ocupados supusieron, en el tercer trimestre el $75,7 \%$ del total, frente al $73,5 \%$ de 2009 .

En Europa es el $19 \%$ y en 1996 estaban en el $20 \%$ y en el $21 \%$, respectivamente. El objetivo europeo de alcanzar el $20 \%$ del PIB en 2020 no se ha cumplido.

5 En 2008 contaba con 2,5 millones de empleados, una cifra que no dejó de reducirse hasta 2014, cuando bajó del millón. A partir de 2015, comenzó un ligero pero constante aumento en el empleo.

6 Julio Sequeiros (5 de mayo de 2019): El Tamaño de la empresa y el sistema productivo español. La Voz de Galicia. A Coruña.

7 Investigación y desarrollo $(I+D)$ es un término que se aplica a todas las actividades que realiza una empresa para buscar nuevos conocimientos científicos o tecnológicos (investigación), que serán aprovechados por la empresa (desarrollo) para la producción de nuevos materiales, productos, servicios o mejora de los mismos.
} 
progreso técnico y la productividad del trabajo a nivel agregado. Estas actividades de $\mathrm{I}+\mathrm{D}$ son procesos costosos no exentos de incertidumbre, pero permiten a las empresas obtener beneficios debido a la diferenciación y competitividad de sus productos y al poder de mercado que adquieren en relación con sus competidores.

El tejido empresarial español, el 1 de enero de 2020, contaba con 3.404 .428 millones de empresas, que daban empleo a 19,18 millones de trabajadores, según los datos del Directorio Central de Empresas (DIRCE) —donde se aplica la adaptación realizada por el Instituto Nacional de Estadística (INE, 2020) del concepto estadístico de empresa introducida por primera vez en los datos referidos a 1 de enero de 2019- y de la EPA.

Una característica sobre el total de ocupados es que 0,88 millones apenas tienen educación primaria $(5 \%)$ y 4,91 millones solo cuentan con la primera etapa de la educación secundaria (26\%). Si los agrupamos a todos, tenemos casi un tercio del total de trabajadores que mayoritariamente cuenta con una baja formación.

Al respecto, el gobernador del Banco de España argumentaba que el capital humano del tejido empresarial español debe mejorar su cualificación, pues presenta una desventaja en relación a nuestras economías de referencia. En España, según Eurostat, el 40,5\% de los autónomos y el $35,1 \%$ de los empresarios tienen un nivel de estudios bajo, frente al $24,8 \%$ de los autónomos europeos y el $20,1 \%$ de los empresarios (Hernández de Cos, 2019).

\subsection{Las microempresas}

De los 3,4 millones de empresas, solamente 279.000 tienen seis o más asalariados; las empresas restantes son microempresas, autónomos sin asalariados o empresas que cuentan con un único asalariado o no más de cinco. Así, tendríamos a casi al $40 \%$ de los asalariados españoles trabajando en aproximadamente tres millones de microempresas. Un dato a considerar es que básicamente cuentan con trabajadores de baja cualificación, los cuales, en el mejor de los casos, alcanzan la enseñanza obligatoria.

El segmento de la microempresa representa lo más típico del tejido empresarial español. Es absolutamente dominante en sectores como restauración, hostelería, comercio al por menor, construcción, reparaciones, reformas... Sectores en los que la productividad del trabajo es muy reducida, y en los que, en estos tiempos de COVID-19, se desata una intensa competencia entre los trabajadores por los empleos disponibles, empujando a los salarios a la baja. Además, y esto es relevante, son sectores orientados hacia la satisfacción de la demanda interna, muy apartados de la competencia internacional.

Estas microempresas trabajan en sectores muy sensibles al ciclo económico, creando empleos abundantes y de baja calidad en las fases de expansión y expulsando mano de obra en igual cantidad en las fases de contracción. Podría decirse, y sería cierto, que este fenómeno se produce en prácticamente todas las economías europeas. Lo particular y específico del caso español es el enorme tamaño que tiene este sector en la economía española con empresas de reducido tamaño en sectores como el turismo, la hostelería y la construcción.

Aquí reside uno de los problemas más relevantes de la economía española: el tamaño, ya que con menos de diez trabajadores, realmente, se pueden hacer muy pocas cosas. 


\subsection{Las pequeñas y medianas empresas}

Las pequeñas empresas son las más de 206.000 que comprenden entre 10 y 49 asalariados que emplean unos tres millones de trabajadores. Para estas empresas, la legislación laboral se torna más compleja cuando superan los 50 trabajadores, siendo relativamente frecuente que una empresa prefiera constituir otra nueva antes que superar dicha cantidad.

Las medianas empresas son las casi 22.000 que se sitúan entre los 50 y los 249 asalariados, dando empleo a unos 2,4 millones. En total, las 228.000 pequeñas y medianas empresas ocupan a 5,4 millones de trabajadores, agrupando otro tercio del empleo. Las pymes, que generan el $62 \%$ del valor añadido, representan lo más característico del sistema productivo, aunque nuestro país es superado por Italia, Grecia y Portugal. Por tanto, las pymes deben ser el objetivo primordial de la política económica de cualquier Gobierno.

En última instancia, las 228.000 pymes, con sus 5,4 millones de empleos, conforman la columna vertebral del tejido empresarial de nuestro país. Su inconveniente proviene de su reducido «tamaño», que tradicionalmente se considera como una desventaja competitiva por su limitada productividad y crecimiento, dificultades propias para su expansión internacional, bien por inversión extranjera directa o por exportación.

Aunque es preciso matizar que el interés suscitado por las empresas medianas, como activas protagonistas del comercio internacional, se remonta años atrás, cuando fueron parte de la solución a la Gran Recesión con sus activas exportaciones. Interés que se ha visto fortalecido por una creciente atención hacia estas empresas con cualidades de campeones ocultos que operan en el mercado medio (middlemarket) y que se suman a las nuevas tendencias del comercio internacional ${ }^{8}$, que emerge con la pandemia del coronavirus.

La mayor atención prestada a las pymes desde el estallido de la anterior crisis se debe a su dinamismo exportador. Aunque no por ello lo tienen fácil para igualar a las Mittelstand, que, por su alta especialización, son empresas de nicho y, generalmente, de productos intermedios e innovadores.

Las Mittelstand constituyen el $95 \%$ del tejido productivo alemán, y como empresas medianas emplean entre 100 y 200 trabajadores. En este caso, el tamaño sí que importa, porque cuanto más grandes son, mayor resistencia tienen. Siendo muy conscientes de la importancia de invertir en $I+D$, ya que les permite transformar e innovar sus procesos productivos y ser más competitivos internacionalmente. En términos país, Alemania invierte en I+D un 2,94\% del PIB, frente al 1,24\% español, situado muy por debajo de la media europea del 2,12\%. España, en 2018, no había recuperado el nivel de inversión pública en $\mathrm{I}+\mathrm{D}$, presentando una importante brecha con la Unión Europea (UE). El esfuerzo no solo está lejos del promedio comunitario, sino que la brecha aumenta cada año. La convergencia que tuvo lugar hasta 2008, cuando se redujo la distancia a medio punto porcentual, se ha convertido en una clara divergencia, de modo que en 2018 la distancia era de casi nueve décimas, aproximadamente la misma que en 2000 (0,88\%).

La explicación de esta distancia, entre España y la media de la UE en términos de I+D, no hay que buscarla en el potencial $D$

8 Entre las nuevas tendencias del comercio internacional destaca la «internacionalización digital», que ofrece ahora más que nunca enormes oportunidades de negocios, sobre todo para las pymes, dado que reduce los costes logísticos, los cobros y pagos, la formalización de los contratos y los servicios auxiliares a la exportación, así como los servicios financieros alternativos a la banca tradicional. 
económico. Si tomamos los valores medios de la UE-28 como índice 100, la renta per cápita española alcanzaría los 91 puntos, mientras que la inversión en I+D por habitante se quedaría en 49. En 2018 había cinco países en Europa con menor renta por habitante que España, pero con una mayor apuesta por la I+D (Eslovenia, Estonia, Hungría, Portugal y República Checa).

También contrasta la trayectoria de España en I+D con la de la Unión Europea, que en 2018 ya invertía un $27 \%$ más que antes de la crisis de 2008. Si se compara con China, que durante el periodo 2008-2018 ha duplicado sus niveles de inversión en I+D, y desde 2015 hasta 2018 invierte al mismo nivel que la Unión Europea (ambas economías destinan un $2,12 \%$ de su PIB), durante el periodo 2009-2018, España acumula un aumento del $2,5 \%$, claramente inferior a los crecimientos observados en las otras cuatro grandes economías europeas: Alemania (38\%), Reino Unido (21\%), Italia $(17 \%)$ y Francia $(12 \%)^{9}$. Llama la atención el desigual comportamiento de la inversión pública entre España y Europa. El crecimiento acumulado de la inversión pública en nuestro país entre 2009 y 2018 es del $-9,8 \%$, inferior al dinamismo europeo (10,5\%). Curiosamente, mientras que España pierde peso en Europa, la misma Europa lo hace frente a China.

Así las cosas, las pymes españolas compiten desde sus capacidades distintivas, destacando su espíritu emprendedor, que les permite crear nuevos negocios, identificar nuevas oportunidades y demostrar una gran flexibilidad para adaptarse a los requerimientos del mercado interno y externo. Estas capacidades distintivas se combinan con otras que no lo son tanto, como el tamaño y la formación de los

9 Para más detalle véase el «Informe COTEC 2020». trabajadores, que representan un inconveniente para que puedan desenvolverse en entornos innovadores que favorezcan la productividad. La productividad de las pequeñas y medianas empresas españolas es un $40 \%$ inferior al de las alemanas, aunque su menor productividad se compensa por un menor coste unitario ${ }^{10}$.

Al respecto, es preciso destacar que la secuencia entre tamaño y productividad demuestra que a medida que se avanza en tamaño, la productividad que se alcanza es mayor. Al encontrarse la dimensión empresarial y la productividad tan relacionada, y ser esta última el factor clave del crecimiento del PIB per cápita a largo plazo, no es de extrañar que exista una fuerte correlación entre el tamaño de las empresas y el nivel de renta per cápita. Lo cual indica que los determinantes de la dimensión empresarial coinciden, en buena medida, con la productividad.

Los resultados relativos de la empresa española, en cuanto a su dimensión y eficiencia productiva, contrastan con la fortaleza de sus exportaciones y, más concretamente, con el aumento de las ventas exteriores en la zona euro y con el sostenimiento de la mismas globalmente, situación que expresa su firmeza competitiva. La explicación de esta aparente paradoja la encontramos, como revelan numerosos estudios, en que otros factores, distintos a los costes y precios relativos (tradicionales determinantes de la competitividad), desempeñan un papel relevante en el dinamismo mostrado por los productos españoles en los mercados internacionales.

Aunque resulte contradictorio, la explicación está en la heterogeneidad del tejido $\square$

10 El costo unitario se calcula a partir de los costos variables y fijos incurridos en el proceso de producción. El cálculo del costo unitario es: (costos fijos totales + costos variables totales)/total de unidades producidas. 
empresarial español, donde encontramos grandes empresas exportadoras que logran altos niveles de productividad y eficiencia que ocupan posiciones de liderazgo en los mercados internacionales, junto con otras numerosas firmas de menor tamaño que presentan una gran eficiencia productiva, más volcadas al mercado interior y expuestas a la competencia externa. Así, la fortaleza competitiva de la economía española descansaría en el grupo de grandes empresas dinámicas y eficientes exportadoras. Si bien, este no es un rasgo que diferencie a España de otros países, pues las exportaciones se concentran generalmente en las grandes empresas, por lo general multinacionales (Gandoy y Álvarez, 2017).

No obstante, durante los últimos años, sobresalen las medianas empresas, que han incrementado su dinámica competitiva exportadora, utilizando la estrategia del destino geográfico, donde combinan los mercados maduros y emergentes. Así, la elevada concentración de las exportaciones en el mercado europeo $^{11}$ (con mucho, nuestro principal cliente), uno de los más exigentes y con mayor capacidad de compra del mundo, ha favorecido la penetración exportadora en otras economías avanzadas, al mismo tiempo que progresivamente lo hacían en las economías emergentes, impulsoras durante las últimas décadas del crecimiento de las importaciones. No obstante, el todavía limitado grado de penetración en estas economías pone de relieve la necesidad de que continúen diversificando la cartera de destinos de sus exportaciones, sin descuidar, claro está, las posiciones en los mercados tradicionales como el europeo.

11 Del total mundial, España exporta a la UE el 71,3, a América Latina, en torno al 5,5\%, siendo algo superior al que mantiene con EE UU (4,9\%) y con Canadá $(4,7 \%)$.
Por último, se puede constatar, según los análisis sobre la calidad de las exportaciones españolas, una creciente presencia de productos industriales más sofisticados y de mayor calidad. Los esfuerzos de las empresas para ajustar sus productos a la demanda mundial y avanzar en la diferenciación de su producción, les ha permitido defender su posición competitiva en actividades altamente expuestas a la competencia internacional, al ofrecer una favorable relación calidad-precio (Gandoy y Álvarez, 2017).

Se hace vital, pues, conseguir vencer el factor crítico de las pymes españolas en relación con el tamaño asociado a la productividad, y no solo para lograr una mayor penetración en los mercados internacionales, sino también como una de las principales respuestas a los retos y vulnerabilidades del crecimiento de la economía española.

El crecimiento es un fenómeno complejo por el que, gracias a la acumulación de cantidades crecientes de factores de producción de mayor calidad y de técnicas más eficientes, las economías producen más y mejores bienes y servicios. Es, por tanto, un proceso dinámico al que es consustancial la modificación de la composición de la producción y la especialización, de modo que este tipo de cambio estructural puede ser considerado como uno de los hechos estilizados del crecimiento económico (Kuznets, 1975).

En primer lugar, el propio crecimiento económico y la elevación de los niveles de renta per cápita influyen en el patrón de consumo y, por tanto, en la demanda relativa de los diferentes bienes y servicios. A largo plazo, el crecimiento de la renta per cápita suele ir acompañado de determinadas transformaciones estructurales que favorecen su continuidad o hacen más equitativa su distribución entre $\triangleright$ 
la población ${ }^{12}$. Como resultado, cambia la estructura sectorial de la economía y su desarroIlo. De hecho, el desarrollo económico ${ }^{13}$ se caracteriza por la aparición de nuevos bienes y servicios de mayor calidad, impulsando nuevos sectores productivos que van adquiriendo mayor peso en el conjunto de la economía.

En segundo lugar, los diferentes sectores productivos se caracterizan por la utilización de distintas tecnologías y, por tanto, por sus diferentes niveles de productividad total de los factores (PTF) ${ }^{14}$ y distintos grados en la intensidad en el uso del capital, así como diferentes ritmos de progreso técnico. Así mismo, el tipo de especialización productiva influye en los niveles sectoriales y agregados de productividad total de los factores y en sus niveles de crecimiento. Los cambios en la estructura productiva de una economía afectarán a su crecimiento y al logro de mayores niveles de desarrollo.

Una anomalía de la economía española, durante las últimas décadas, es que el aumento de la productividad total de los factores ha sido realmente escaso, e incluso mostró tasas de crecimiento negativas durante buena parte de la primera década del siglo xxı. La PTF ha

12 Para más detalle, véase Myro (2017).

13 Durante la década de 1980, los conceptos de «crecimiento y desarrollo» se distanciaron. El «desarrollo» adquirió una mayor dimensión humana, referida a la distribución del ingreso, a la satisfacción de necesidades básicas como la salud, la educación y la elevación del nivel de vida en general. Mientras que "crecimiento" significa un aumento del tamaño de la economía por la asimilación o adquisición de bienes y servicios, acompañado de un aumento de la población. Así, cuando una economía se desarrolla, se encuentra mejor cualitativamente, pero cuando una economía crece, se hace mayor cuantitativamente. El crecimiento cuantitativo y la mejoría cualitativa podrían seguir caminos diferentes. Naciones Unidas admitió que el crecimiento económico podría producirse incluso sin consecuencias sociales positivas para una determinada sociedad (Izquierdo, 2002).

14 La productividad total de los factores se define como la diferencia entre la tasa de crecimiento de la producción y la tasa media de crecimiento de los factores utilizados para obtenerla, donde los factores de ponderación son las participaciones de cada factor en la renta nacional. En otras palabras, la suma de contribuciones de los factores productivos (trabajo y capital) y la PTF coincide con la tasa de variación del PIB. También se obtiene a partir del modelo expresado en términos per cápita, como diferencia entre la tasa de crecimiento de la productividad del trabajo y la del capital por trabajador, esta última ponderada por la participación del capital en la renta. crecido durante los últimos veinte años aproximadamente un $0,2 \%$ en promedio, dos décimas menos que la media de la eurozona, de acuerdo con las estimaciones de la Comisión Europea $^{15}$. Este bajo crecimiento tiene un coste en términos de riqueza. Un cálculo sencillo permite ilustrar que, si la PTF se hubiese comportado como en la zona euro, la renta por trabajador español alcanzaría casi el 90\% de la media de la eurozona, frente al $79 \%$ que representaba en 2018 (Eurostat, 2018). El salario medio español es un $21 \%$ inferior al salario medio bruto de los países de la Unión Europea, según se desprende del VII Monitor Anual Adecco sobre Salarios 2019.

España cuenta, además, al menos con otras dos anomalías en comparación con otros países de la eurozona. La primera consiste en que la productividad de las pequeñas y medianas empresas de nueva creación es más reducida. Estas nuevas empresas muestran niveles de productividad inferiores a la media de su sector, lo que sugiere la existencia de un periodo de aprendizaje para que converjan hacia la eficiencia media. La literatura, al explicar los resultados y los niveles de productividad entre los diferentes segmentos de empresas, señala tres aspectos claves: i) nivel de capitalización, ii) esfuerzo y resultados innovadores y iii) cualificación de los trabajadores.

La otra anomalía es que el crecimiento del empleo explica dos tercios del crecimiento económico registrado desde 1995; mientras que el tercio restante se explica por la contribución de la acumulación de capital y de la productividad total de los factores. El aumento de la ocupación y la baja productividad han sido las dos $D$

15 Las cuentas de la productividad y el crecimiento económico se incorporaron como novedad en el Reglamento N $N .{ }^{5} 549 / 2013$ del Parlamento Europeo y del Consejo, de 21 de mayo, relativo al sistema europeo de cuentas nacionales y regionales de la Unión Europea. 
caras de la expansión de los sectores del turismo, de la construcción y de los servicios. Según los informes elaborados por IESE-Adecco ${ }^{16}$, España es el tercer país de la Unión Europea; detrás se encuentran Polonia y Portugal, con un menor rendimiento por hora trabajada.

El resultado de estas anomalías es que la economía española mantiene un tejido empresarial dominado por un gran número de empresas de reducida dimensión, escasamente productivas, con baja especialización y formación, $y$, por otra parte, cuenta con un grupo menor formado por empresas de mayor tamaño (multinacionales) que se encuentran a la altura de sus homónimas europeas.

Entre las empresas industriales, que son las de mayor tamaño, se comprueba que cuentan con una posición de ventaja con relación tanto en el esfuerzo inversor como en los resultados innovadores y de personal cualificado. Esto se comprende muy rápidamente, teniendo en cuenta que poseen tecnologías y conocimientos de los que carecen por lo general las pequeñas y medianas.

Por tanto, las pequeñas y medianas empresas tienen que plantearse el crecimiento como un objetivo permanente. Deben estar abiertas ante las oportunidades de fusiones y adquisiciones, acuerdos y alianzas estratégicas, con el propósito de favorecer las economías de escala que les habilitan las oportunidades que suponen tener un mayor tamaño. De esta manera, sería más factible reestructurar el tejido empresarial español en beneficio de una mayor productividad, innovación e internacionalización, traducido en un más vigoroso crecimiento.

\footnotetext{
16 Informes elaborados por el Centro Internacional de Investigación del IESE, que incorporan y sintetizan toda una serie de indicadores sobre el mercado laboral a partir de los datos estadísticos de Eurostat, el INE y las distintas oficinas nacionales de estadística.
}

De manera que nos encontramos con un tejido empresarial donde la alta importancia de las pymes en la economía española hace sentir la incesante necesidad de acometer una «reactivación», haciendo que las microempresas se conviertan en pequeñas, estas en medianas, las medianas en grandes y las grandes en multinacionales.

Al mismo tiempo, deben operar un importante cambio de mentalidad en cuanto a cuáles son las variables para competir; no deben utilizar solo las ventajas comparativas de los precios de los factores productivos, es decir, tienen que abandonar la idea de competir solo en costes si quieren tener ventajas competitivas, al tiempo que han de incorporar nuevos factores relacionados directamente con la sostenibilidad, la digitalización, la calidad y la marca que incorporan valor añadido. Este es el reto y los desafíos principales que tienen las pymes españolas para los próximos años.

Así que todo apunta en la misma dirección. Las pequeñas y medianas empresas deben prepararse lo más velozmente posible para poder hacer frente a los desafíos y competir con el mayor de los éxitos en el nuevo tablero del ajedrez global del mundo pos-COVID-19.

\subsection{La gran empresa}

La gran empresa se refiere a la que tiene más de 250 asalariados. De este tipo hay unas 4.800, que dan empleo a 5,35 millones de personas, otro tercio del total de la población en activo, un porcentaje algo menor que en la Unión Europea, donde Reino Unido (ya fuera de la UE), Irlanda, Alemania o Francia emplean en torno al $37 \%$ y el $47 \%$ de la población activa.

Este segmento cuenta con una característica estratégica que lo convierte en particular. $\triangleright$ 
Una gran cantidad se ha internacionalizado y algunas son grandes multinacionales globales, sobre las cuales las políticas tienen que actuar con cautela, teniendo en cuenta que los países sin excepción las apoyan, y más en estos momentos tan particulares de la COVID-19. Las posiciones internacionales de liderazgo, que mantienen las grandes empresas y los bancos españoles con especial relevancia en América Latina, las sitúan en la vanguardia y la punta de lanza de la economía española ${ }^{17}$.

Las grandes empresas españolas, en su expansión internacional, han desplegado una estrategia gradualista. Como indica la teoría, lo hacían conforme acumulaban habilidades y experiencias, mejoraban la competitividad y gestión de las distintas ventajas que ofrecían en los países. Así procedieron desde los primeros años de 1990, cuando iniciaron la expansión internacional hacia América Latina (Casilda Béjar, 2002), región que les permitió abrir una nueva etapa que las conduciría a convertirse en multinacionales globales.

Abro nota. La construcción por parte de España de grandes empresas multinacionales significa un hecho relevante en la historia económica mundial. Hecho al que no se le ha prestado la atención merecida. Construir grandes multinacionales, incluidas las entidades financieras, es un proceso que a los países con más experiencia y poseedores de grandes firmas les ha llevado cuando menos más de medio siglo, como es el caso de las multinacionales estadounidenses, y las más antiguas, como las alemanas o inglesas, han tardado varios. Es un dato a tener muy en cuenta. Cierro la nota.

En cuanto a los niveles de productividad, prácticamente, no ofrecen diferencia alguna

17 Para un amplio análisis sobre las grandes multinacionales españolas y su presencia global, véase Multinacionales españolas en un mundo global y multipolar (Casilda Béjar, 2011). con sus competidores, y como sector altamente internacionalizado es el mayor responsable de la actividad exportadora e inversora española. Son también responsables de gran parte de la innovación en los productos y los procesos productivos. Su gran reto es liderar la «cuarta revolución industrial», que incluye la automatización, la robótica, la inteligencia artificial, la nanotecnología, la biotecnología, y tecnologías genéricas que inciden sobre un conjunto amplio de sectores y que, por esa misma razón, pautan los incrementos y calidad de la producción. También anticipan escenarios que harán caer las líneas divisorias entre algunos sectores, y no solo industriales, sino también financieros, cuya competencia se ha exacerbado.

Lo ha hecho con la llegada de las fintech (empresas tecnológicas-financieras que abiertamente compiten con los bancos pero que al mismo tiempo establecen acuerdos y alianzas conjuntas) y las bigtech (las grandes corporaciones tecnológicas), que han acuñado el acrónimo GAFA (Google, Amazon, Facebook, Apple). A las GAFA se les añaden otras como Microsoft, Samsung y Paypal, más las asiáticas Baidu, Alibaba y Tencent, conocidas como BAT. En conjunto, representan un muy poderoso big bang para el negocio financiero que compite directamente con los bancos, y que les preocupa por los siguientes motivos: i) los menores costes operativos marcan su competitividad, ii) la positiva ratio costes-ingresos permite ampliar su modelo de negocio, iii) las fintech como las GAFA cuentan con un portentoso poder de mercado ${ }^{18}$.

18 Un ejemplo es Amazon, que es una página web, un medio de pago, una fórmula algorítmica y una potente red logística. De esta manera se desentiende de toda relación con lo productivo, con lo que supone de reducción de costes, y una vez convertido en el actor dominante, extrae rentabilidad presionando a cada uno de los participantes en la cadena, al mismo tiempo que obtiene cantidades ingentes de datos que los convierte en valor. 
Para la gran empresa se ha producido un hito destacado en cuanto a su estrategia de producción (sin tener en cuenta las amplias y considerables implicaciones que trae consigo la COVID-19). Hasta ahora, su estrategia pasaba por la deslocalización en perjuicio de la localización, que, como es conocido, desde la llegada del presidente de Estados Unidos, Donald Trump, se encuentra estimulada por políticas proteccionistas que finalmente han desembocado en la guerra comercial que libra Estados Unidos con China, y que ha adquirido dimensiones globales tras las críticas experiencias del corte de suministros de las cadenas de abastecimiento desde China, como consecuencia de la crisis de la COVID-19.

De manera que las grandes empresas españolas, que estratégicamente deslocalizaron su producción y la concentraron generalmente en China, casi con toda seguridad, finalizada la pandemia del coronavirus, la revisarán profundamente, y especialmente la concentrada o que mayoritariamente pasa por China.

\section{Las empresas españolas y la estrategia de deslocalización}

La estrategia de la deslocalización no es un fenómeno aislado, sino que ha existido bajo diversas formas y nombres, aunque no con la dimensión, la intensidad y aceleración que adquirió a partir de la década de 1990, años de mayor expansión económica en los países avanzados y de impulso a la integración económica por la reducción de las barreras comerciales, en especial de los aranceles. Esta mayor presión competitiva se asocia con la deslocalización, como mecanismo para la reducción de los costes de las empresas, entre ellos los laborales, que aumenta el atractivo de fabricar en zonas con salarios más bajos. Además, la aparición de nuevos y extensos mercados emergentes con claras perspectivas de expansión ofrecían grandes oportunidades de negocio.

A su vez, ha ido acompañado de un fuerte aumento de la competencia entre países que se disputan la captación de IED, utilizando para ello incentivos fiscales, laborales y de otro signo. Es, pues, una etapa inversora caracterizada por la deslocalización de la producción y la creciente movilidad del comercio internacional. Pero esta dinámica está decayendo y algo importante está sucediendo, que puede dar un giro importante en las estrategias de deslocalización de las multinacionales en sentido inverso, aunque, si es necesario, continuarán aprovechándola como arma competitiva. Sin embargo, diversos movimientos indican que se ha iniciado un viaje de retorno de la producción hacia los países de origen.

Una de las principales manifestaciones del proceso de globalización económica es la internacionalización de los procesos productivos. Ante la creciente competencia de las economías emergentes, las empresas de las economías avanzadas - fundamentalmente multinacionales, pero no solo- han diseñado nuevas estrategias, entre las que destaca la división internacional de la producción, léase cadenas de valor. Esta forma de organización implica que la cadena de valor de un producto se divide en distintas etapas productivas que se localizan allí donde pueden obtenerse menores costes y se disponga de un entorno que garantice la viabilidad del proceso productivo (infraestructuras de transporte y comunicaciones, ventajas de exportación a los mercados internacionales, seguridad jurídica de las inversiones y la propiedad privada y una economía estable). El resultado ha sido un extraordinario desarrollo de cadenas globales de producción en las que intervienen múltiples empresas y países.

El objetivo de esta estrategia es mejorar la posición competitiva de las empresas mediante la disminución de los costes de producción, en particular los costes laborales. Así, en los últimos años, las empresas de las economías avanzadas han ubicado las cadenas de valor más rutinarias e intensivas 
en trabajo manual en economías con inferiores niveles de renta y salarios. A esta deslocalización de actividad y empleo se añade la pérdida ocasionada por el cierre de empresas incapaces de afrontar la intensificación de la competencia internacional.

La industria española ha participado activamente en este proceso de internacionalización, aumentando progresivamente su dependencia de bienes intermedios importados desde las últimas dos décadas del siglo veinte. En un primer momento, lideraron el proceso la fabricación de vehículos de motor y las industrias intensivas en mano de obra como la confección, que, tras la adhesión de España a la Unión Europea, tuvo que hacer frente a un fuerte incremento de la competencia comunitaria y extracomunitaria. Desde mediados de los años noventa del siglo veinte, los principales protagonistas han sido las industrias intensivas en tecnología -maquinaria de oficina o equipos electrónicos-, donde las cadenas de valor globales han mostrado una mayor actividad.

Las estadísticas de comercio en valor añadido permiten constatar la creciente participación española en cadenas de valor globales, tanto mediante la transformación de bienes intermedios importados (muy especialmente en la fabricación de vehículos, donde los inputs externos suponen prácticamente la mitad del valor exportado) como, en menor medida, a través de la provisión de inputs intermedios a otros países para su incorporación en las exportaciones (manufacturas más vinculadas a los recursos naturales y las industrias metálicas básicas).

Esta vía de internacionalización, que avanzó rápidamente en la segunda mitad de los años noventa del siglo veinte, detiene su progresión a raíz de la crisis económica de 2008-2009, como ocurrió en el resto de las economías desarrolladas. En parte, ello se debió al colapso en los flujos comerciales ligados a la crisis internacional. No obstante, en España, como en otros países, un número destacado de empresas ha retornado su actividad hacia su lugar de origen o hacia economías avanzadas más próximas geográficamente.

Este fenómeno se le conoce como estrategia Coca-Cola: producir más localmente, más próximo al consumidor, pero sin dejar de hacerlo globalmente. Las causas tienen que ver tanto con alteraciones en los costes de producción, desde el encarecimiento del transporte o el aumento del coste laboral en los países emergentes, como por las dificultades surgidas en la coordinación de procesos productivos dispersos, de forma que se garanticen los estándares de calidad exigidos, así como por los requerimientos de seguridad laboral y salud.Y, por supuesto, todo ello con el trasfondo de la inacabada guerra comercial entre Estados Unidos y China ${ }^{1}$.

\footnotetext{
Para más detalle sobre la guerra comercial entre China y Estados Unidos, las posiciones respectivas frente a la globalización y el proteccionismo, así como la crisis de 2008 y la estrategia de deslocalización de la empresa multinacional, véase, Casilda Béjar, R. (2019).
}

Fuente: Gandoy y Álvarez (2017) y elaboración propia.

El ejemplo más reciente de relocalización, que afecta de lleno a la economía española y concretamente a la industria del «automóvil», es la decisión francesa enmarcada en una nueva estrategia de localización de su industria automovilística. El Gobierno francés percibe la crisis de la COVID-19 como una oportunidad única para revertir algunas políticas industriales que considera perjudiciales para el país, como la deslocalización llevada a cabo por el
Grupo PSA y Renault, dos de los fabricantes de automóviles más importantes en nuestro país.

«La industria automovilística francesa ha deslocalizado demasiado y debe replegarse. La repatriación de la producción debe ser «la contrapartida» a las ayudas que el Estado les conceda a estos grupos para superar la presente coyuntura» (Le Maire, La Vanguardia, 12 de mayo de 2019). El presidente francés, $D$ 
Emmanuel Macron, presentó un plan de 8.000 millones de euros de ayuda al sector automovilístico, para hacer frente a la crisis, que incluye el compromiso de relocalización de parte de la producción de los grupos PSA y Renault de fabricar en Francia sus vehículos «limpios, eléctricos e híbridos».

Desde el Gobierno de España se desea impulsar junto con las comunidades autónomas la reindustrialización de España. También las grandes empresas y organizaciones empresariales se suman al impulso por considerar que la industria es un motor de investigación, innovación y conocimiento. Además, la crisis de la COVID-19 ha evidenciado la necesidad de contar con cadenas de suministro industriales que han resultado ser estratégicas para hacer frente a este tipo de crisis sanitarias.

Queda claro que la deslocalización practicada durante los últimos treinta años busca los menores costes posibles. Pero la automatización, la robótica y la inteligencia artificial han reducido el incentivo del bajo coste laboral. Por tanto, hoy producir localmente ofrece una mayor seguridad ante las rupturas de las cadenas de suministro y más aún en industrias estratégicas. La relocalización que se pretendía llevar a cabo durante la próxima década de 2030, ahora, tras las experiencias acontecidas, se intensificará notablemente.

Con anterioridad, en Estados Unidos surgió el movimiento llamado «reapuntalamiento», que pretendía la «relocalización» de las empresas estadounidenses. El reapuntalamiento comenzó en EE UU antes de la elección del presidente Donald Trump y su eslogan de referencia, «América Primero». La idea partió de Harry Moser en 2010. El movimiento representa un esfuerzo para que las empresas estadounidenses regresen y creen nuevos empleos industriales en el país. La iniciativa trabaja con las industrias y fabricantes para ayudarlos a reconocer su potencial de ganancias locales, así como el papel fundamental que desempeñan en el fortalecimiento de la economía utilizando la producción nacional ${ }^{19}$.

También se observa un proceso de reapuntalamiento en los países más avanzados de la Unión Europa, atrayendo las producciones deslocalizadas en las zonas de menor desarrollo del Sudeste Asiático. Este proceso de regreso se vio favorecido por la Gran Recesión y los ajustes competitivos salariales utilizados. Otros motivos se encuentran en la subida de los costes laborales relativos, así como por la mayor exigencia en la legislación social.

Resulta significativo que The Economist abriese un debate online y una votación a favor o en contra del reshoring (regreso). La pregunta era: ¿tienen la obligación las multinacionales de mantener una fuerte presencia en sus países de origen? La fuerte presencia se refería a la inversión, al empleo, la producción y las compras, al menos en proporción a sus ventas. El no era defendido por el economista especializado en comercio internacional y defensor del libre comercio, Jagdish Bhagwati, que obtuvo un $46 \%$, frente al sí que logró el defendido por Harry Moser, un 54\% (Casilda Béjar, 2019).

Las grandes empresas españolas, ante todo este puzle, no deben descuidarse, pues tienen nuevos caminos por delante que recorrer, aunque muchas de ellas ya lo han iniciado, abordando profundos procesos de cambio, en unos casos, con más énfasis en el talento y las personas; en otros, con desarrollo de modelos organizativos centrados en los procesos y en el cambio tecnológico innovador, que, junto con la marca, conforman las señas de identidad $\triangleright$ de su «modelo de negocio».

19 Para más detalle, véase: www.reshorenow.org 


\section{El Pacto Verde de la Unión Europea y la activación del tejido empresarial español}

España cuenta con niveles de actividad económica muy inferiores a la media europea, mientras que el paro y la desigualdad son bastante superiores.

La crisis de la COVID-19 impone la prioridad absoluta de frenar la destrucción de empresas y la reactivación del tejido empresarial español a favor del empleo y la recuperación de las rentas.

A los efectos, adquieren un protagonismo determinante las grandes empresas privadas (las 4.800 que emplean 5,35 millones de trabajadores), al igual que las grandes empresas públicas, que también deben ser agentes dinamizadores e impulsores, y no meros diques de contención, como sucede con la Sociedad Española de Participaciones Industriales (SEPI), dependiente del Ministerio de Hacienda, que practica un enfoque meramente administrativo, y que más bien, como sucedía desde la creación del holding público Instituto Nacional de Industria (INI), debería formar parte del Ministerio de Industria para crear, impulsar y ejecutar política industrial. Adviértase que la idea nada tiene que ver con recuperar el histórico INI, sino más bien con revertir el escaso interés que la política viene prestando a las empresas públicas y su protagonismo industrial (Jiménez Asensio, 2020 [blog]) ${ }^{20}$.

Por su parte, la Comisión Europea, con el Pacto Verde ${ }^{21}$ y la digitalización, ha diseñado la

20 Donde comienzan admitiendo que la COVID-19 ha puesto de manifiesto la importancia crucial de lo público, pero también sus insuficiencias.

21 El Pacto Verde - la ruta que con anterioridad al coronavirus se había marcado la UE para erradicar los gases de efecto invernaderoabarca todos los sectores de la economía, especialmente los del transporte, la energía, la agricultura, la renovación de edificios y las industrias, como la siderurgia, el cemento, los textiles, los productos químicos y las TIC. estrategia de recuperación y crecimiento económico pos-COVID-19, mediante inversiones en soluciones sostenibles que incorporan la calidad del trabajo, donde la participación de las empresas, el compromiso de los ciudadanos y de todas las partes interesadas son cruciales para su éxito.

Reactivar el tejido empresarial español concuerda con la visión de un modelo avanzado productivo e innovador, alineado con la estrategia del Pacto Verde, que definió la presidenta de la Comisión Europea, Ursula von der Leyen, «como una excelente oportunidad de aprovechar la crisis de la pandemia del coronavirus para convertir a la economía europea en más sostenible, resiliente y digital»».

En la reactivación del tejido empresarial español se debe prestar una cuidada atención a las pequeñas y medianas empresas, desde el compromiso con el Pacto Verde y la digitalización, como vectores transformadores del sistema productivo europeo, que será más sofisticado, y más equilibrado y respetuoso con el cambio climático.

En su programa como presidenta de la Comisión Europea, Ursula von der Leyen (noviembre de 2019) dijo:

El Pacto Verde se propone reforzar las pequeñas y medianas empresas, columna vertebral de la Unión Europea, que representan más del $95 \%$ del tejido empresarial y el $85 \%$ de los puestos de trabajo creados en los últimos cinco años. Son las que emprenden, ofrecen formación profesional a nuestros jóvenes y representan todo lo bueno de nuestra economía. Necesitamos más jóvenes emprendedores, innovadores y tecnologías de vanguardia, como fueron, hace apenas diez años, los gigantes tecnológicos de esta generación. Quiero que a las pequeñas y medianas empresas les resulte más fácil convertirse en grandes innovadores. Debemos $D$ 
seguir desarrollando la financiación para que se conviertan en grandes innovadoras del futuro. Por ello, presentaré una estrategia específica para las pymes con el fin de garantizar que puedan prosperar, reduciendo la burocracia y mejorando su acceso al mercado. Concluiremos la Unión de los Mercados de Capitales para garantizar que tengan acceso a la financiación que necesitan para crecer, innovar y expandirse. Para ello, se creará un fondo público-privado especializado en ofertas públicas de pymes, con una inversión inicial de la UE que podrá contar también con la aportación de inversores privados. (Von der Leyen, 2019)

A los responsables de la formulación de políticas, el Pacto Verde les asigna un papel importante en el apoyo de las pequeñas y medianas empresas. Esto se debe a que estas empresas se alinean bien con las políticas que seleccionan ganadores (pickingwinner) o que buscan mejores prácticas, y porque ayudan a legitimar estrategias de especialización inteligente. Además, apoyan aquellas que son especialistas en nichos internacionales, ya que demuestran cómo logran diversificar sus ventas en todo el mundo, aumentando así su solidez frente a las caídas de los mercados locales.

El Pacto Verde, según el sondeo del Eurobarómetro realizado para la Comisión Europea (abril de 2019), informa que los europeos estaban muy preocupados por el cambio climático y a favor de tomar medidas en toda la UE para hacerle frente $y$, particularmente, para impulsar la economía y el empleo. En este punto, los principales resultados del sondeo han sido: más de ocho de cada diez encuestados están de acuerdo en que promover la experiencia de la UE en tecnologías limpias en países no miembros puede beneficiar económicamente $(81 \%)$, mientras que tomar medidas en materia de cambio climático hará que las empresas sean más innovadoras y competitivas (79\%). Una gran mayoría está de acuerdo en que reducir las importaciones de combustibles fósiles procedentes de fuera de la UE puede aumentar la seguridad energética y beneficiarnos desde el punto de vista económico (72\%). Siete de cada diez encuestados (70\%) están de acuerdo en que la adaptación de los acuerdos por el cambio climático puede tener resultados positivos para los ciudadanos de la UE.

La hoja de ruta del Pacto Verde hace un recorrido por buena parte del conjunto de la economía europea a través de los siguientes epígrafes: i) energía limpia, ii) industria sostenible, iii) renovar y construir edificios sostenibles, iv) movilidad sostenible, v) biodiversidad, vi) de la granja a la mesa y vii) eliminar la contaminación. Para llevarlo a cabo, elabora una propuesta de inversiones y de instrumentos de financiación, dentro del marco para una transición justa e inclusiva.

EI Pacto Verde contempla apoyar financieramente a las pymes más afectadas por la transición hacia la economía verde. Para ello, contará con el «Mecanismo para una transición justa», que contribuirá a movilizar 100.000 millones de euros, como mínimo, durante el período 2021-2027.

De manera que el Pacto Verde es un instrumento de movilización de recursos para una reconstrucción, reconstitución y renovación del modelo económico europeo en aras de hacerlo más resiliente, sostenible, digital y competitivo.

El Pacto Verde y la digitalización, sin dudas, debe ser la gran apuesta española que acelere la transición ecológica y las inversiones en energías limpias que estimulen la creación de nuevas empresas en sectores con futuro y empleos de calidad. 


\section{Creación del Instituto Verde y Digital de la Pequeña y Mediana Empresa Española}

En el actual contexto, resulta deseable impulsar propuestas que faciliten que el tejido empresarial español, constituido, como se ha visto, principalmente por pymes, aproveche esta movilización de recursos para avanzar en la transición hacia un modelo productivo verde y digital. En esta línea, se lanza la propuesta para la creación del «Instituto Verde Digital de la Pequeña y Mediana Empresa Española», que se basa principalmente en los siguientes puntos no definitivos:

- El instituto se crea con las aportaciones públicas-privadas y las provenientes del Fondo de Recuperación Europeo, que cuenta con 750.000 millones de euros (500.000 no reembolsables y 250.000 millones en préstamos). A España le corresponden 140.446 millones de euros ( $11 \%$ del PIB), de los cuales serían 77.324 millones de euros no reembolsables y 63.122 millones en préstamos.

- El instituto puede verse reforzado con aportaciones del Pacto Verde mediante el «Mecanismo para una transición justa». El mecanismo otorga apoyo para contribuir a la movilización de un mínimo de 100.000 millones de euros durante el periodo 2021-2027 en las regiones más afectadas, a fin de mitigar el impacto socioeconómico de la transición hacia la economía verde. También se cuenta con la importante contribución del presupuesto de la UE a través de todos los instrumentos directamente relacionados con la transición.
- El instituto puede recibir otros apoyos financieros provenientes del Banco Europeo de Inversiones, así como de otras instituciones europeas y españolas.

- El instituto también puede recibir aportaciones del «sector privado» en sus diferentes vertientes, donaciones a fondo perdido y otras por medio de contribuciones en especie.

- El instituto contribuye a reforzar la sostenibilidad en el modelo de negocio y en la cultura empresarial de los clientes y de los empleados mediante las acciones pertinentes de información y formación.

- El instituto no excluye que su ámbito de actuación se extienda a la microempresa.

- El instituto se encuentra relacionado y en plena sintonía con el Pacto Verde y la digitalización como los vectores transformadores del sistema productivo europeo, que será más sofisticado, sostenible y socialmente más equilibrado.

Esta propuesta y sus ideas no son definitivas ni cerradas, sino abiertas para enriquecerlas y hacer viable la creación del «Instituto Verde y Digital de la Pequeña y Mediana Empresa».

\section{Conclusiones}

Asumiendo que el tejido empresarial español necesita ser reestructurado y reactivado con el objetivo central de alumbrar un «nuevo modelo productivo", alineado con el Paco Verde y la digitalización de la Unión Europea, es el momento de aprovechar intensamente esta nueva oportunidad, que en esta ocasión ofrece la COVID-19, para acometer con decisión, no exenta de audacia, la reindustrialización de $\triangleright$ 
la economía española. Si bien, es meridianamente cierto que dicha reindustrialización se hace recurrente en nuestro país cada vez que aparece una nueva crisis.

Además, la economía española apostó gran parte de su futuro en los servicios, entre ellos el financiero, ya que una economía moderna necesita un sistema financiero eficiente y potente que proporcione la estabilidad y la financiación adecuadas al tejido empresarial para su crecimiento y desarrollo. Sin embargo, no apostó con igual intensidad por el sector industrial, lo cual ha desembocado en un desequilibrio intersectorial que es necesario recomponer.

Siendo muy consciente de que el sistema productivo de un país no se reestructura de la noche a la mañana, pues forma parte de la esencia misma de su economía, hay que establecer amplios consensos entre las políticas públicas y los agentes económicos privados, dado que se corresponde con un proceso que requiere, ante todo, continuidad en la colaboración a largo plazo.

Hoy la prioridad pasa por salvar el tejido empresarial, el empleo y las rentas familiares, para así abordar, de la mejor manera posible, la reactivación de la economía española y, con ello, conseguir un tejido empresarial potente, eficiente, competitivo y alineado con el Pacto Verde y la digitalización como pilares básicos de crecimiento económico pos-COVID-19.

Ahora bien, las ideas, reflexiones y propuestas que he realizado no son un canto a las buenas intenciones, ni un ramillete de buenas voluntades ni un discurso al uso cargado de oportunismo. No, lo que trato, lo que pretendo, es alumbrar hacia dónde queremos ir y dónde queremos estar, y la manera de avanzar para conseguir un tejido empresarial o, lo que es lo mismo, un sistema productivo eficiente, competitivo y robusto, generador de riqueza y bienestar.

De conseguirlo, se dejaría a las generaciones futuras un ejemplo de lo que significa la unidad de acción, la determinación y la solidaridad, todos ellos valores muy propios de la cultura española y europea.

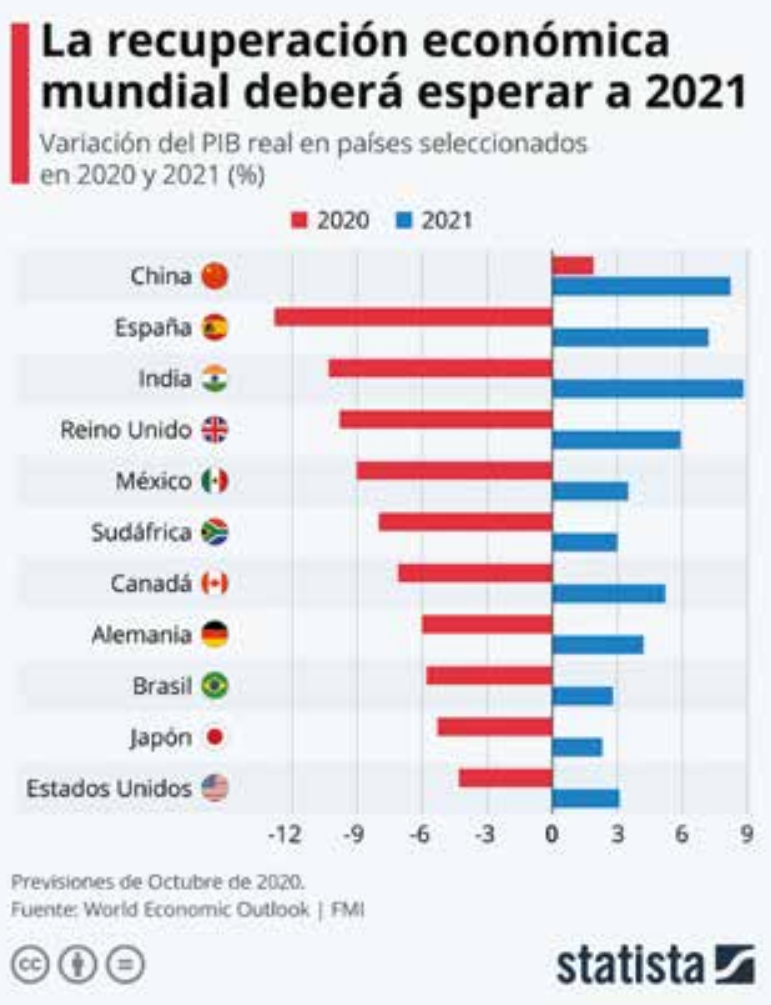

\section{Bibliografía}

Casilda Béjar, R. (2002). La década dorada. Economía e inversiones españolas en América Latina 1990-2000. Servicio de Publicaciones de la Universidad de Alcalá. Madrid.

Casilda Béjar, R. (2011). Multinacionales españolas en un mundo global y multipolar. ESIC Editorial.

Casilda Béjar, R. (2019). Capitalismo. Crisis y Reinvención. Tirant.

COTEC (2020). Informe COTEC 2020. 
Gandoy, R., y Álvarez, M. E.(2017). Sector Industrial. En García Delgado, J. L., y Myro, R. (Dirs.), Lecciones de Economía Española. Civitas Thomson Reuter.

Hernández de Cos, P. (7 de mayo de 2019). Retos de la economía española. La productividad y el tejido empresarial. Asamblea anual del Instituto de la Empresa Familiar. Banco de España. https://www.bde.es/f/webbde/GAP/Secciones/ SalaPrensa/IntervencionesPublicas/Gobernador/hdc070519.pdf

INE (2020). Estructura y dinamismo del tejido empresarial en España. Directorio Central de Empresas (DIRCE).

Izquierdo, G. (2002). La economía mundial contemporánea y sus procesos de cambio. Instituto de Estudios Económicos (IEE). Madrid.

Jiménez Asensio, A. (2020). Declaración sector público. Por un sector público capaz de liderar la recuperación [Blog]. https://rafaeljimenezasensio.com/declaracion-sector-publico/

Kuznets, S. (1975). Demographic Components in Size-Distribution of Income.

Le Maire, B. (12 de mayo de 2019). Declaraciones a La Vanguardia.

Myro, R. (2017). Crecimiento económico y cambio estructural. En García Delgado, J. L., y Myro, R. (dirs.), Lecciones de Economía Española. Civitas Thomson Reuter.

Sequeiros, J. (5 de mayo de 2019). El tamaño de la empresa y el sistema productivo español. La Voz de Galicia. A Coruña.

Von der Leyen, U. (noviembre de 2019). Mi agenda para Europa. Una unión que se esfuerza por lograr más resultados. Orientaciones políticas para la próxima Comisión Europea 2019-2024. Comisión Europea. 